\title{
Ectopic liver on gall bladder serosa a case report and brief review of literature
}

\author{
Mahendra Lodha ${ }^{1, *}$, Hemanshu Pande ${ }^{2}$, Suresh kumar ${ }^{3}$, Ashok Puranik ${ }^{4}$ \\ ${ }^{1,2}$ Assistant Professor, ${ }^{3}$ Senior Resident, ${ }^{4}$ Professor, All India institute of Medical scienses, Jodhpur, India
}

*Corresponding Author:

Email: drmahendralodha@gmail.com

Received: $25^{\text {th }}$ February, 2018

Accepted: 09 $9^{\text {th }}$ March, 2018

\begin{abstract}
Ectopic liver is a very rare developmental anomaly of liver, it is rairly diagnosed preoperatively because of rairrity of condition and very scarcely produces any symtom,it is missed in radiology .we report a case of ectopic liver which was diagnosed intraoperatively on laparoscopy as a incidental finding while doing a right radical nephrectomy,it is not clear in literatur what is to be done for this incidentaly diagnosed normal ecctopic liver while doing other surgery. A brief review of its prevalance, embriology, diagnosis, and pathology which develop in ectopic liver will be disccused in this review.
\end{abstract}

Keyword: Ectopic liver, Renal cell carcinoma, Laprosocpy, Incidental.

\section{Introduction}

Development of liver is a complex, which takes place during $4{ }^{\text {th }}$ week of intrauterine life, liver develop from fore gut as a budding from ventral fore gut. ${ }^{1}$ Ectopic liver occur as an abnormal migration of embryonal hepatic cell to ectopic site, it is called as acccessory lobe of liver when attached to parent liver it can be found on various site above and below the diaphragm, like gallbladder, hepatoduodenal ligament, stomach, retroperitoneal area, mediastinum and pleural cavity, out of which gallbladder serosa is the most common site for ELT. ${ }^{2}$

\section{Case History}

A 50 year male patient who visited hospital for routine checkup was incidentaly detected a right kidney mass on ultrasonography of abdomen, further work up for this renal mass in right kidney was done by contrast CT Scan of abdomen and pelvis. CT Scan finding was sujjestive of early stage right renal mass, considering early lesion in kidney without any metastasis, this patient was posted for laprosopopic radical nephrectomy, after doing anaesthesia work up. During diagnostic laproscopy for this surgery we found a small liver tissue on serosal surface of gallbladeer approximately size of $2 \times 2 \mathrm{~cm}$.in size, which was resembling morphologicaly to parent hepatic tissue, without any nodularity and cavitaion, with a singel blood supply coming directly from ventral surface of liver (Fig. 1), our case falls in type 3 described by collan. ${ }^{1}$ Right renal mass was confined to gerota"s fascia, without any peritoneal metastasis and ascitis in peritoneal cavity. Because this liver tissue resembled morphologicaly as parent liver tissue so thinking as a ectopic liver, no active intervention was done for ectopic liver and right radical nephrectomy was done for right renal mass. Post operative this patient is completely normal without any metastsis. Retroscpectively when CT images of this patient was reviewd back by our radiologist they found a small tissue approximately size of $1 \times 1 \mathrm{~cm}$ is size resembling to native liver tissue in echotexture, which was missed on radilogy study preoperatively.

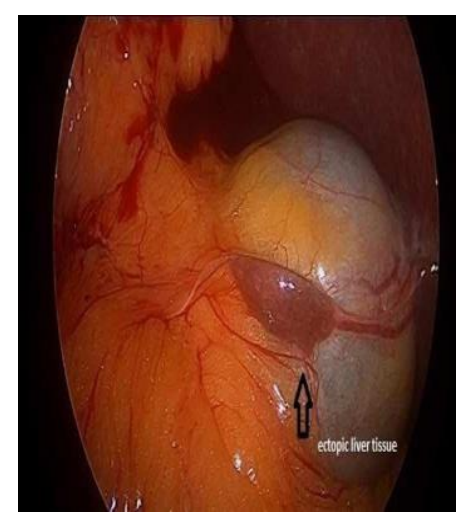

Fig. 1: Laparoscopic view of Ectopic liver

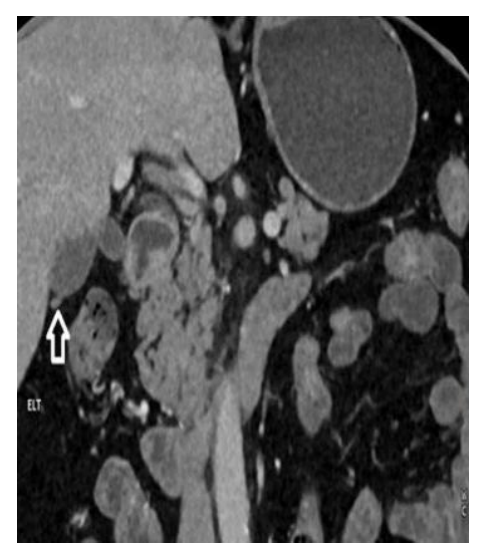

Fig. 2: CT scan image of Ectopic Liver 


\section{Discussion}

In development, the hepatic diverticulum comprises the liver and biliary tree, and it appears late in the third week or early in the fourth week of gestation. The foregut endoderm of the hepatic diverticulum develops into the liver parenchyma (hepatocytes) and the epithelial lining of the biliary tract. The hepatic diverticulum divides to form a small ventral portion, the future gall bladder, and a larger cranial portion, the liver primordium. Island of liver tissue which is found seprate from parent liver, is called as aberrant liver tissue or ectopic liver or heterotrophic liver tissue,this tissue does not have any direct connection with parent liver, it is very rare anomaly, only hundreds of cases has been reported in literature. ${ }^{3}$ Review by eiserch in 1940 of 5500 autopsies only 13 cases of ectopic liver were demonstrated, out of which 3 were on gall bladder surface size and site of ectopic liver tissue may vary, ${ }^{4}$ it may occur on above or below the diaphragm. Most common site of ectopic liver tissue is serosal surface of gallbladder. ${ }^{5}$ Other site are hepatoduodenal ligament, stomach, umbilicus, retroperitoneum, mediastinum and pleura. $^{6}$ Collan classified ectopic liver in four broad types. ${ }^{1}$ Accessory liver lobe that can reach a considerable size and is attached to the liver by a stalk. ${ }^{2}$ Small accessory liver lobe which is attached to the liver but is usually small, about 10-30 g in weight. ${ }^{3}$ Ectopic liver which is situated outside the liver without any connection with it. It is usually attached to the gallbladder or intra-abdominal ligaments. ${ }^{4}$ Microscopic ectopic liver which is found occasionally in the wall of the gallbladder.

Hepatic cell of ectopic liver cell resembels to parent liver cell histologicaly and behave like native liver cell. Blood supply is usually from hepatic artery or portal vein, billiary drainage system may be present or absent in ectopic liver. ${ }^{6}$ ELT can develop all pathology which develop in native liver like hepatitis, cirrrhosis, benign and malignant tumor. Benign tumor of ectopic liver in literature as being reported are hemangioma, adenoma, focal nodular hemangioma. ${ }^{7}$ Malignant lesion include HCC, many author had reported that ectopic liver has increased risk for HCC, probalble mechanism for increased incidence of HCC is that they are metabolicaly handikept, it has also been reported that HCC developing in ectopic liver is also at early age.

Arakawa et $\mathrm{al}^{6,7}$ reported that there were $21 \mathrm{HCC}$ cases related to ELT and emphasied that only six cases (27\%)has cirrhosis in parent liver. ELT on GB has less risk of HCC as compare to other ectopic liver tissue outside liver. ${ }^{7,8}$ Normal ectopic liver rairly produces any sign and symptom because of small size and rairty of its prevalance, various reports of incidentaly detected histologicaly normal ectopic liver had been reported while doing laprosocopic cholecystectomy for cholelithiasis ${ }^{5}$ diseased ectopic liver may give symtom like native liver and also may present as a pressure symptom on portal vein, jaundice due to cirrhosis and HCC. ${ }^{5}$ ELT may give acute symptom due to torsion of ectopic liver tissue, and may present as acute abdomen in emergency. ${ }^{6}$ Laprosocpic cholecystectomy has been done for cholelithiaisis with ectopic liver on surface of gallbladder, but it is not clear whether to do cholecystectomy for incidentaly detected ectopic liver, some author has reported to do cholecystectomy for incidentaly detected ectoipic liver on gallbladder because of increased incidence of HCC in ectopic liver,long term study is not clear in this matter. Care should be taken while doing cholecystectomy for ectopic liver situated on GB, because of blood supply is directly from parent liver or from cystic artery ,severe haemorrhage may occur. ${ }^{8}$

\section{Conclusion}

Ectopic liver is a very rare entiety, very rarly diagnosed preoperatively on imaging, it is yet not clear whether routine cholecystectomy should be done for incidentaly detected ectopic liver found on gb surface, although some report of increased incidence of HCC has been reported in ectopic liver on GB.

\section{Conflict of Interest}

Authors do not have any conflict of interest.

\section{References}

1. Collan Y, Hakkiluoto A, Hästbacka J. Ectopic liver. In Annales chirurgiae et gynaecologiae 1978 (Vol. 67, No. 1, pp. 27-9).

2. Arakawa M, Kimura Y, Sakata K, Kubo Y, Fukushima T, Okuda K. Propensity of ectopic liver to hepatocarcinogenesis: case reports and a review of the literature. Hepatology. 1999 Jan 1;29(1):57-61.

3. Watanabe M, Matsura T, Takatori Y, Ueki K, Kobatake T, Hidaka M, Hirakawa H, Fukukmoto S, Shimada Y. Five cases of ectopic liver and a case of accessory lobe of the liver. Endoscopy. 1989 Jan;21(01):39-42.

4. Caygill CP, Gatenby PA. Ectopic liver and hepatocarcinogenesis. European journal of gastroenterology \& hepatology. 2004 Aug 1;16(8):727-9.

5. Iber T, Rintala R. Intrapulmonary ectopic liver. Journal of pediatric surgery. 1999 Sep 1;34(9):1425-6

6. Hamdani SD, Baron RL. Ectopic liver simulating a mass in the gallbladder wall: imaging findings. AJR. American journal of roentgenology. 1994 Mar;162(3):647-8.

7. Leone N, De Paolis P, Carrera M, Carucci P, Musso A, David E, Brunello F, Fronda GR, Rizzetto M. Ectopic liver and hepatocarcinogenesis: report of three cases with four years' follow-up. European journal of gastroenterology \& hepatology. 2004 Aug 1;16(8):731-5.

8. Angquist KA, Boquist L, Domellöf L. Ectopic liver lobule with portal cirrhosis. Acta chirurgica Scandinavica. 1975;141(3):238-41.

Abbreviation: Ectopic liver Tissue(ELT),Right renal mass (RRM). 